\title{
Investigation of the Polycrystalline Silicon PV Cell Efficiency in 3D Approximation versus Electromagnetic Field under Monochromatic Illumination
}

\author{
Adama Ouedraogo $\mathbb{D}^{1,2}$ Boubacar Soro, ${ }^{1,3}$ Ramatou Konate, ${ }^{1}$ Fati Amadou Oumarou, ${ }^{1}$ \\ and Dieudonné Joseph Bathiebo ${ }^{1}$ \\ ${ }^{1}$ Laboratory of Thermal and Renewable Energies, Department of Physics, Unit of Training and Research in Pure and \\ Applied Sciences, Université Joseph Ki-Zerbo, Ouagadougou, Burkina Faso \\ ${ }^{2}$ Centre Universitaire Polytechnique de Kaya (CUP-Kaya), PO Box 232 Kaya, Burkina Faso \\ ${ }^{3}$ Institut des Sciences (IDS), Université Joseph Ki-Zerbo, Ouagadougou, Burkina Faso \\ Correspondence should be addressed to Adama Ouedraogo; damissau@hotmail.com
}

Received 26 June 2021; Revised 30 August 2021; Accepted 5 October 2021; Published 31 October 2021

Academic Editor: Jinn Kong Sheu

Copyright ( 92021 Adama Ouedraogo et al. This is an open access article distributed under the Creative Commons Attribution License, which permits unrestricted use, distribution, and reproduction in any medium, provided the original work is properly cited.

\begin{abstract}
This manuscript is about the electric output of the silicon ( $\mathrm{Si}$ ) photovoltaic (PV) cell versus the electromagnetic field of a radio wave and a monochromatic illumination in three-dimensional (3D) assumptions. The polarisation direction of the electromagnetic wave and power density are fixed. The electromagnetic wave is provided by electromagnetic emission sources such as the telecommunication, radio, or TV antennas. A PV system is installed in the vicinity of an electromagnetic emission source. The current produced by the PV cell is sensitive to electromagnetic field increase more than the electric voltage. The electromagnetic field causes the decomposition of the current into two components which are a transferred current and a leakage current. The transferred component provides the transmitted current to the external load while the leakage component gives the loss of the carrier charge into the junction. Consequently, this decomposition of the current shares the electric power in transferred electric power and leakage electric power. The transferred electric power is obtained only in the intermediate circuit, and the maximum power point (MPP) shifts to the short circuit situation as the junction dynamic velocity becomes the greatest. However, the leakage electric power corresponds to a loss of the minority carrier's charge in the junction during the crossing of the junction. This loss causes a Joule heating effect of the junction. The heating of the junction causes the quality degradation of the PV cell mainly due to the electric component. The solar illumination wavelength is presenting the inversion phenomenon with the maximum of the electrical outputs of the silicon PV cell of around $0.70 \mu \mathrm{m}$ which provides the greatest conversion efficiency. This value has been chosen for the modelling of the radio wave influence. Hence, the conversion efficiency increases when the PV system is far away from the electromagnetic emission source. PV system installation in the vicinity of an electromagnetic emission source is not advised.
\end{abstract}

\section{Introduction}

The silicon photovoltaic (PV) cell is the most used PV technology in the word because of the abundance of silicon in the earth's crust and its none toxicity [1]. In a climate change context, the PV energy is adopted by many developing countries to compensate for the weakness of the electric grid. In the silicon PV cell range, the monocrystalline silicon (mono-Si) solar cell provides better outputs. But it is strongly dependent on environmental parameters such as temperature $[2,3]$. For the Sahel trip, the energy demand is very high, but the ambient temperature is very high. The polycrystalline silicon PV cell is well adapted in this trip because of its resistance to heat more than the mono-Si cell [4]. On the other hand, we assist in the increase of the uses of the technologies as the base transceiver stations (BTS) emitting the electromagnetic field in the 
environment. The proliferation of the BTS antennas because of $4 \mathrm{G}$ and $5 \mathrm{G}$ generates more and more the electromagnetic field. At the same time, the PV systems are particularly used in the rural regions near the BTS antennas to provide electrical energy. The photovoltaic (PV) system installed in the antenna vicinity which is submitted to its influence in rural zone is shown in Figure 1.

In urban zones, we assist also in the simultaneous installations of the PV system and the BTS antennas on the towers and the buildings as shown by the following Figure 2 .

The electromagnetic field can be attenuated during the cross of a PV module. However, its attenuation can be neglected into the polycrystalline PV cell which is an elementary unit of the PV module [6]. The electromagnetic field from radio waves $(9 \mathrm{kHz}$ to $3000 \mathrm{GHz})[7,8]$ is composed of an electric field and a magnetic field which are perpendicular in the plane wave approach. The electric field causes individually the increase of the density of current produced by the PV cell $[3,9]$. However, the voltage provided by the PV cell decreases with the increase of the individual electric field mainly in the open circuit $[3,9]$. This decrease of the open circuit voltage is the cause of the increase of the current due the conduction current creation and not due to the bulk and surface recombination and ionization as suggested in some studies [10]. The magnetic field causes individually the increase of the electric voltage due to the inflexion caused by the magnetic field [11]. The electromagnetic field causes a decomposition of the current produced by the PV cell in two components. One is transferred to the external load, named the transferred current, and the other is lost in the pn junction [12]. This last is called the leakage current [12]. The magnetic field strength is weak, but it cannot be neglected and be deleted in the electromagnetic field produced by the BTS as assumed in some studies [13]. The electromagnetic field as well as the electric field taken alone causes the conduction current which is not considered in some studies [14]. Many works evaluating the influence of the electromagnetic field are carried out in the onedimension (1D) approximation $[12,13,15]$ while this approximation overestimates the solar cell parameters [16]. The three-dimensional (3D) approach allows to take into account the effect of grain size $(\mathrm{g})$ and grain boundary recombination velocity $\left(S_{g b}\right)$. There are more studies on the PV cell performance versus the electromagnetic field. But these works do not provide the current production taking into account the loss in the junction and Joule effect. It is then very instructive to investigate the efficiency of the polycrystalline silicon PV cell in order to recognize where the greatest losses occur and reduce the conversion efficiency. That will allow choosing a good installation position of the PV system in the BTS environment. The present paper investigates the influence of electromagnetic field dependence on the conversion efficiencies of a polycrystalline silicon PV cell under monochromatic illumination in $3 \mathrm{D}$ assumptions.

In order to determine the efficiencies from the calculated density of current and voltage values, the devices were modelled using standard semiconductor device theory, and the magnetotransport equation as well as the continuity equation is solved in Methods and Theories. In the next section,

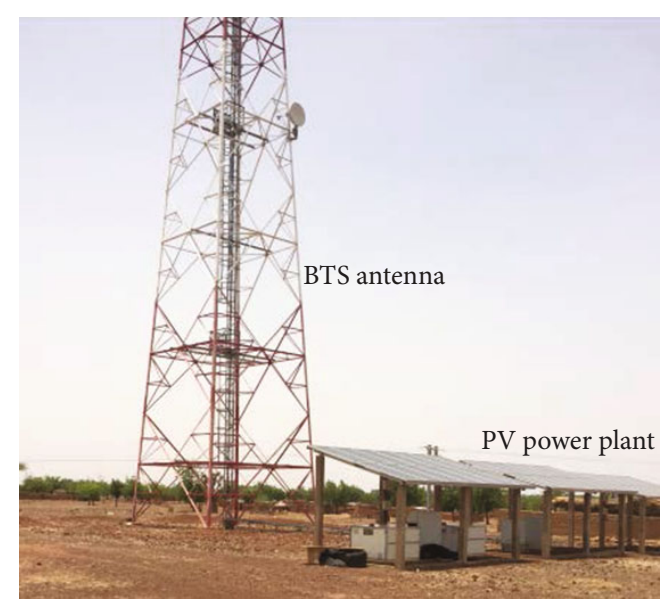

FIgURe 1: PV system in vicinity of the BTS antenna.

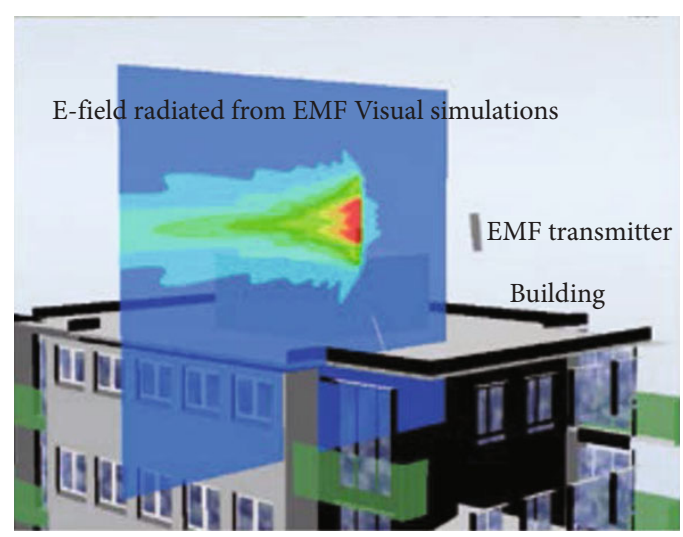

Figure 2: 3D E-field radiated in front of the BTS antenna from EMF visual simulations [5].

Results and Discussions is about the influence of the electromagnetic field, and monochromatic illumination on the electric parameters of the PV cell will be provided. The last section of this study will be about the conclusion on the behaviour of the efficiencies versus the electromagnetic field and monochromatic illumination.

\section{Methods and Theories}

2.1. Electromagnetic Field Components. From Figure 3, the device structure is essentially an emitter $\left(n^{+}\right)$, a $p-n$ junction, a base $(p)$, and a rear face $\left(p^{+}\right)$. It will be considered as the ideal solar cell in this study. The contribution from the base to the photocurrent is greater than that of the emitter [17]. The present work will consider the base as being the center of the generation-recombination phenomena. This analytic study is carried out in the theory of the quasineutral base (QNB) $[17,18]$. The diffusion length is assumed greater than the grain size [19]. For a power density given from the antenna, the polarisation direction is assumed fixed matching to the PV cell orientation tilt, the electromagnetic field from BTS antenna varied versus the distance between the 


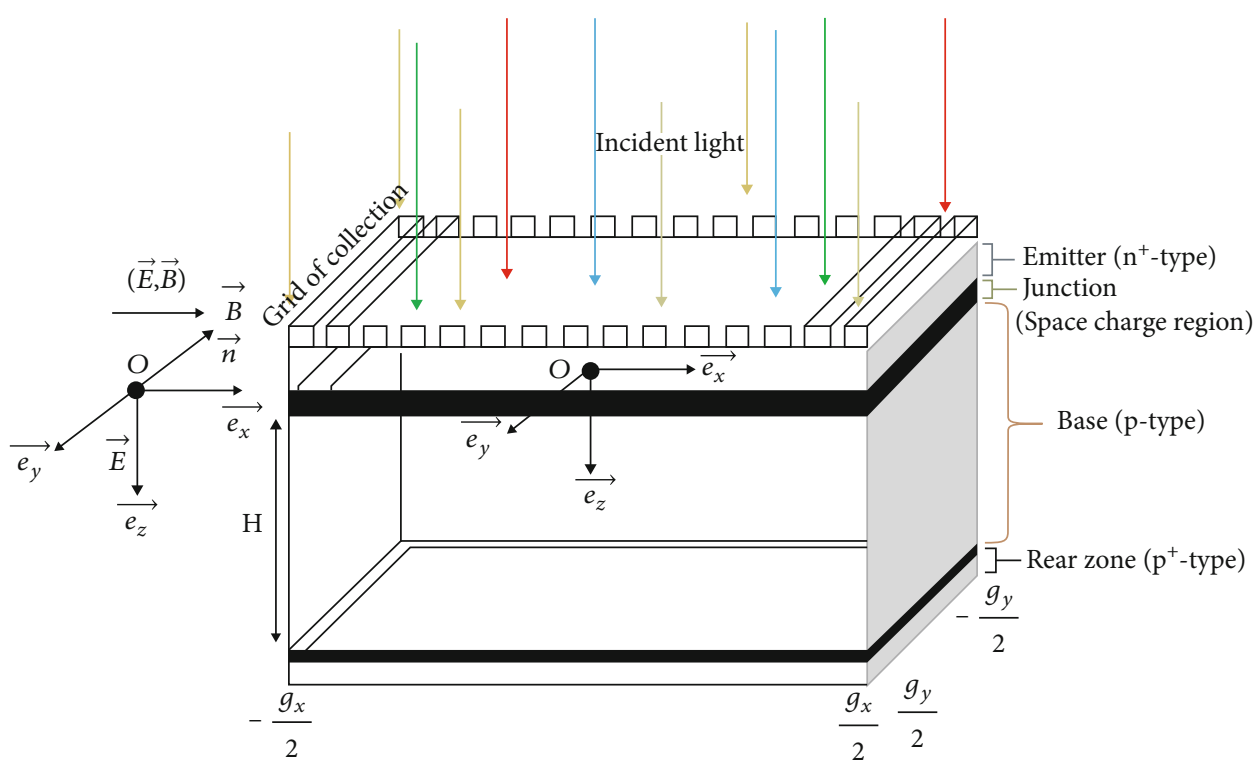

FIGURE 3: PV cell grain under monochromatic illumination and electromagnetic field.

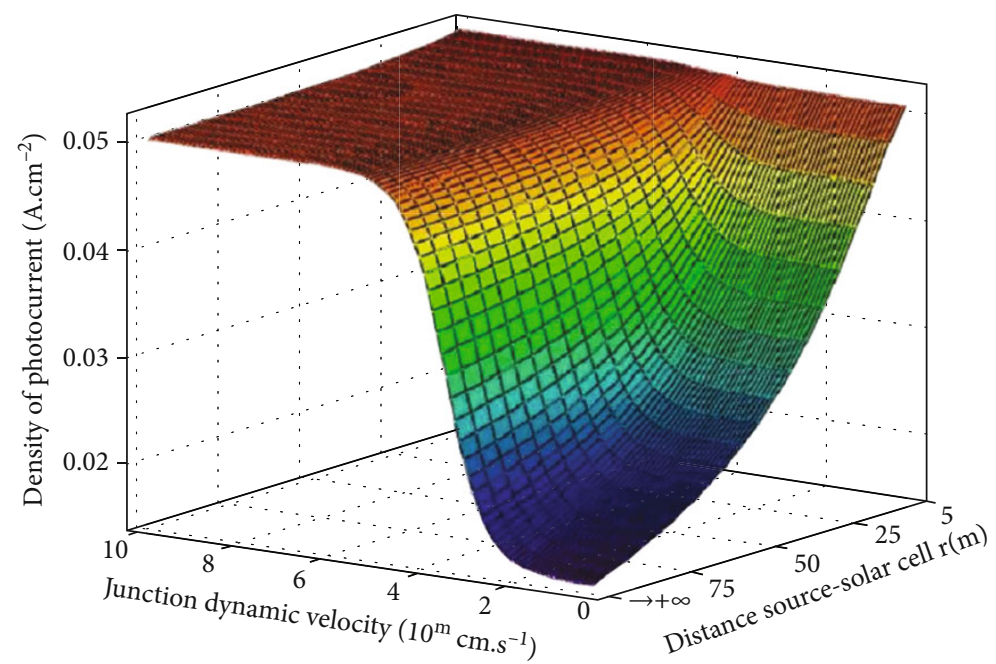

FIGURE 4: Global current versus the junction dynamic velocity $\left(S_{f}\right)$ and the distance emission source-PV cell $\left(L_{\mathrm{n}}=0.015 \mathrm{~cm}, D_{n}=26 \mathrm{~cm}^{2}\right.$ $\left.\cdot \mathrm{s}^{-1}, \mu_{n}=1000 \mathrm{~cm}^{2} \cdot \mathrm{V}^{-1} \cdot \mathrm{s}^{-1}, S_{b}=10^{4} \mathrm{~cm} \cdot \mathrm{s}^{-1}, S_{g b}=10^{3} \mathrm{~cm} \cdot \mathrm{s}^{-1}, g_{x}=g_{y}=3.10^{-2} \mathrm{~cm}, \lambda=0.70 \mu \mathrm{m}, H=0.03 \mathrm{~cm}\right)$.

PV cell and distance. The following Figure 3 presents the polycrystalline solar cell grain under the monochromatic illumination and under an electromagnetic field in the far field zone.

In this figure, $H$ defines the base depth and the grain size following $(O x)$ axis is $g_{x}$ and following $(O y)$ axis is $g_{y}$ with $1 \mu \mathrm{m} \leq g \leq 1 \mathrm{~mm}$ [20]. The PV cell (maximum $10 \mathrm{~cm}$ ), considered as the smallest part of a PV module, is made up of many other basic units each having their own shape named as a grain. The grains vary in size, but they are always smaller compared to the cell. The grain is a fundamental parameter for the polycrystalline solar cell. It presents the same structural and functional characteristics as a solar cell. This work is about a polycrystalline PV cell, not about the PV module, because on the PV module, it is important to take into account the attenuation caused by the protection grids which will definitely be screening and attenuating the electromagnetic waves penetrating into a PV module.

After the crossing of the grain of the solar cell, the expressions of the electromagnetic field components are given by the following [6]:

(i) Electric component is

$$
\vec{E}(x, t)=E_{0} \vec{e}_{z} \cos (x \omega \sqrt{\varepsilon \mu}-\omega t)
$$

(ii) Magnetic component is 


$$
\vec{B}(x, t)=-\frac{E_{0} \sqrt{\mu_{r} \varepsilon_{r}}}{c} \vec{e}_{y} \cos (x \omega \sqrt{\mu \varepsilon}-\omega t)
$$

The electromagnetic field reaches the solar cell when $t$ $=0$ and $x=y=0$. There are many possible angles for the electromagnetic field to reach the grain [21]. We assume that the polarisation direction of the electromagnetic field is fixed and it matches the PV system orientation tilt. In this frequency range, the electromagnetic field cannot cause the ionization of the silicon matter [22]. The electromagnetic field considered in this work disposes of an energy less than $12 \mathrm{eV}$ [8], i.e., the electromagnetic field has a frequency ranging up to $3.10^{12} \mathrm{~Hz}$. The electromagnetic field orientation is perpendicular with the junction of the solar cell and consequently with the junction of the selected grain. Then, the electric field and magnetic field becomes the following:

(i) Electric component is

$$
\vec{E}(0,0)=E_{0} \vec{e}_{z}
$$

(ii) Magnetic component is

$$
\vec{B}(0,0)=-\frac{E_{0} \sqrt{\mu_{r} \varepsilon_{r}}}{c} \vec{e}_{y}
$$

The amplitude of the electric field can be obtained through the next equation [23]:

$$
E_{0}=\frac{1}{2 r} \sqrt{\frac{P_{r} \cdot Z_{0}}{\pi}}
$$

where $r$ is the distance between the sources of the emission of the electromagnetic field and the solar cell, $P_{r}(W)$ is an isotropic antenna radiating a power in free space, and $Z_{0}=$ $377 \Omega$, the characteristic impedance in free space. The antenna power density is fixed in $P_{r}=2 \mathrm{MW}$ in free space and $r \in[5 m,+\infty[$. The electromagnetic field increases with the weakening of the distance $r$ [23].

2.2. Magnetotransport Equation. The density of the current named magnetic-transport equation provided by the PV cell under electromagnetic field is given by $[15,16,24,25]$

$$
\vec{J}_{n}=\vec{J}_{d}+\vec{J}_{c}+\vec{J}_{\text {ind }} \text {, }
$$

here $\vec{J}_{d}$ gives the diffusion current, $\vec{J}_{c}$ provides the contribution of the electric component called conduction current, and $\vec{J}_{\text {ind }}$ provides the contribution of the magnetic component named the induction current [15].

Following the orientation of the electric field and of the magnetic field given in Figure 1, the solving of the magnetotransport equation gives the different components of the photocurrent expressed in the following equation:
$\vec{J}_{n}=\left\{\begin{array}{l}J_{n x}=\frac{e D_{n} \mu_{n} B_{y}}{1+\left(\mu_{n} B_{y}\right)^{2}} \cdot \frac{\partial \delta(x, y, z)}{\partial z}-\frac{e D_{n}}{1+\left(\mu_{n} B_{y}\right)^{2}} \cdot \frac{\partial \delta(x, y, z)}{\partial x}-\frac{e \mu_{n}^{2} B_{y} E}{1+\left(\mu_{n} B_{y}\right)^{2}} \cdot \delta(x, y, z), \\ J_{n y}=e D_{n} \frac{\partial \delta(x, y, z)}{\partial y}, \\ J_{n z}=\frac{e D_{n}}{1+\left(\mu_{n} B_{y}\right)^{2}} \frac{\partial \delta(x, y, z)}{\partial z}+\frac{e D_{n} \mu_{n} B_{y}}{1+\left(\mu_{n} B_{y}\right)^{2}} \cdot \frac{\partial \delta(x, y, z)}{\partial x}+\frac{e \mu_{n} E}{1+\left(\mu_{n} B_{y}\right)^{2}} \cdot \delta(x, y, z) .\end{array}\right.$

Equation (7) facilitates the establishment of the continuity equation. It gives the expression of the density of the photocurrent into the base of the solar cell and consequently in the grain. The next point will provide the establishment of the continuity equation and its solution.

2.3. Continuity Equation. The continuity equation [26, 27] is given by the following equation:

$$
\frac{\partial \delta(x, y, z)}{\partial t}=\frac{1}{e} \operatorname{div}\left(\overrightarrow{J_{n}}\right)+G_{n}(z)-R_{n}(x, y, z) .
$$

If the illumination is permanent, the state is steady [26]. Hence, $\partial \delta(x, y, z) / \partial t=0 ; R_{n}(x, y, z)$ gives the recombination rate of the electronic charge after generation. Its expression is $R_{n}(x, y, z)=\delta(x, y, z) / \tau_{n}$ [28] with $\tau_{n}$, the electron's life time, and $G_{n}(z)$, the generation rate.

The compilation of equations (7) and (8) leads to the following equation.

$$
\begin{aligned}
C_{x} \frac{\partial^{2} \delta(x, y, z)}{\partial x^{2}} & +C_{y} \frac{\partial^{2} \delta(x, y, z)}{\partial y^{2}}+\frac{\partial^{2} \delta(x, y, z)}{\partial z^{2}} \\
& +\frac{\mu_{n} E_{0}}{D_{n}} \frac{\partial \delta(x, y, z)}{\partial z}+\frac{G(z)}{D_{n}^{*}}-\frac{\delta(x, y, z)}{L_{n}^{* 2}}=0
\end{aligned}
$$

where $C_{x}=1, C_{y}=D_{n} / D_{n}^{*}, \quad$ and $D_{n}^{*}=D_{n} /\left(1+\left(\mu_{n} \cdot B_{0}\right)^{2}\right)$ are the diffusion coefficient depending on magnetic field and $L^{* 2}=D^{*} \cdot \tau_{n}$ is the diffusion length depending on the magnetic field. The carrier's generation rate for a monochromatic incident illumination can be written as follows [29]:

$$
G(z)=\alpha(\lambda) \cdot \phi_{0} \rho(\lambda) \cdot[1-\rho(\lambda)] \cdot e^{-\alpha(\lambda) \cdot z} .
$$

$\alpha(\lambda)$ and $\rho(\lambda)$ are, respectively, absorption and reflection coefficients in the $\lambda$ wavelength, and $\phi_{0}$ is the incident photon flow.

The excess minority carrier's density, the general solution of the continuity equation, is given by $[19,30,31]$

$$
\delta(x, y, z)=\sum_{j} \sum_{k} Z_{j, k}(z) \cdot \cos \left(C_{x j} x\right) \cdot \cos \left(C_{y k} y\right),
$$

with $C_{x j}=C_{j} / \sqrt{C_{x}}$ and $C_{y k}=C_{k} / \sqrt{C_{y}}$. The constants $C_{x j}$ and $C_{y k}$ are found through the grain in grain boundary conditions which are

$$
\left.\frac{\partial \delta(x, y, z)}{\partial x}\right|_{x= \pm g_{x} / 2}=\mp \frac{S_{g b}}{2 D_{n}^{*}} \cdot \delta\left( \pm \frac{g_{x}}{2}, y, z\right),
$$




$$
\left.\frac{\partial \delta(x, y, z)}{\partial y}\right|_{y= \pm g_{y} / 2}=\mp \frac{S_{g b}}{2 D_{n}^{*}} \cdot \delta\left(x, \pm \frac{g_{y}}{2}, z\right) .
$$

Replacing equation (11) into equations (12) and (13) leads to the following transcendental equations:

$$
\begin{gathered}
C_{x j} \cdot \tan \left(C_{x j} \cdot \frac{g_{x}}{2}\right)=\frac{S_{g b}}{2 D_{n}^{*}}, \\
C_{y k} \cdot \tan \left(C_{y k} \cdot \frac{g_{y}}{2}\right)=\frac{S_{g b}}{2 D_{n}^{*}} .
\end{gathered}
$$

The coefficients $C_{y k}$ and $C_{x j}$ are the solutions of these transcendental equations which are solved numerically.

Equation (9) is a second-order differential equation at constant coefficient with a second member. Using equation (11), equation (9) allows to find the next equation.

$$
\frac{\partial^{2} Z_{j, k}(z)}{\partial z^{2}}+\frac{\mu_{n} E_{0}}{D_{n}} \frac{\partial Z_{j, k}(z)}{\partial z}-\frac{1}{L_{j, k}^{2}} \cdot Z_{j, k}(z)=-\frac{G(z)}{D_{j, k}}
$$

In this equation, the term $\left(\mu_{n} E_{0} / D_{n}\right)\left(\partial Z_{j, k} / \partial z\right)$, which is a first derivative in relation with position $z$, is similar to a damping term [24], $1 / L_{j, k}^{2}=C_{j}^{2}+C_{k}^{2}+1 / L_{n}^{* 2}$ and $1 / D_{j, k}=16$ $\cdot \sin \left(C_{x j}\left(g_{x} / 2\right)\right) \sin \left(C_{y k}\left(g_{y} / 2\right)\right) / D_{n}^{*}\left[\sin \left(C_{x j} g_{x}\right)+C_{x j} g_{x}\right][\sin$ $\left.\left(C_{y k} g_{y}\right)+C_{y k} g_{y}\right]$. The resolution of this equation gives the next equation as solution

$$
Z_{j, k}(z)\left[A_{j, k} \cosh (\gamma z)+B_{j, k} \cdot \sinh (\gamma z)\right]+K_{j, k} \cdot e^{-\alpha(\lambda) z}
$$

with $\quad \beta=-\left(L_{E} / 2 \cdot L_{n}^{2}\right), \quad L_{E}=\mu_{n} \tau E_{0} \quad[32], \quad \gamma=-(1 / 2)$ $\left[\left(\mu_{n} E_{0} / D_{n}\right)^{2}+4 / L_{j, k}\right]^{1 / 2}$ and $K_{j, k}=-\left(\alpha(\lambda) \phi_{0}(\lambda)(1-\rho(\lambda)) /\right.$ $\left.D_{j, k}\left[\alpha(\lambda)^{2}-\alpha(\lambda)\left(L_{E} / L_{n}^{2}\right)-1 / L_{j, k}^{2}\right]\right)$. The solution taking account $j$ and $k$ is provided by

$$
Z(z)=\sum_{j} \sum_{k} Z_{j, k}(z)
$$

The real constants $A_{j, k}$ and $B_{j, k}$ are found using the solar cell's boundary conditions:

(i) At the junction $(z=0)$ :

$$
\left.D_{n}^{*} \frac{\partial Z_{j, k}(z)}{\partial z}\right|_{z=0}=S_{f} \cdot Z_{j, k}(0)
$$

(ii) At the rear face $(z=H)$ :

$$
\left.D_{n}^{*} \frac{\partial Z_{j, k}(z)}{\partial z}\right|_{z=H}=-S_{b} \cdot Z_{j, k}(H)
$$

$S_{f}$ is the junction dynamic velocity, and it quantifies the number of excess carriers which are collected in junction in a given operating condition (open circuit, intermediate operating point, and short circuit) [32-34]. $S_{b}$ is the back surface recombination velocity, and it quantifies the losses of the carrier charge at the solar cell's rear side [32]. The solution 17 leads to the general solution in replacing it in equation (11).

The determination of the density of excess minority carrier charge provides the way to study the electric parameter as the density of the photocurrent, the photovoltage, and the electric power which will be evaluated in the next section.

2.4. Photocurrent Density Expressions. Equation (7) is used to find the density of the photocurrent. This equation shows that the current is a vector where its strength is expressed by the following equation:

$$
\begin{aligned}
J_{p h} & =\frac{1}{g_{x} g_{y}}\left\{\left[\left.\int_{-g_{x} / 2}^{g_{x} / 2} \int_{-g_{y} / 2}^{g_{y} / 2} J_{n x}\right|_{z=0} d x d y\right]^{2}\right. \\
& \left.+\left[\left.\int_{-g_{x} / 2}^{g_{x} / 2} \int_{-g_{y} / 2}^{g_{y} / 2} J_{n y}\right|_{z=0} d x d y\right]^{2}+\left[\left.\int_{-g_{x} / 2}^{g_{x} / 2} \int_{-g_{y} / 2}^{g_{y} / 2} J_{n z}\right|_{z=0} d x d y\right]^{2}\right\}^{1 / 2} .
\end{aligned}
$$

The integration of the different components allows to find the current as following that we are going to call global current:

$$
J_{p h_{j, k}}=e R_{j, k}\left[D_{n}^{*}\left(\beta A_{j, k}+\gamma B_{j, k}-\alpha(\lambda) K_{j, k}\right)+\mu_{n}^{*} E_{0}\left(A_{j, k}+K_{j, k}\right)\right],
$$

with $\mu_{n}^{*}=\mu_{n} /\left(1+\left(\mu_{n} B_{0}\right)^{2}\right)$ the electronic mobility coefficient depending on magnetic field and $R_{j, k}=4 \sin \left(c_{x, j}\left(g_{x} / 2\right)\right)$. $\sin \left(c_{y, k}\left(g_{x} / 2\right)\right) / c_{x, j} \cdot c_{y, k}$. The global current after taking accounts $j$ and $k$ is

$$
J_{p h_{j, k}}=\sum_{j} \sum_{k} J_{p h_{j, k}}
$$

The totality of the photocurrent density is not transferred to the external load. One part is leaked in the parasite resistances [12]. It is called the leakage photocurrent. But another part is transferred to the external load [12]. It will be named the transferred photocurrent. The PV boundary conditions at the junction is $\partial Z_{j, k}(z) /\left.\partial z\right|_{z=0}=S f \cdot Z_{j, k}(0) /$ $D_{j, k}$. In this expression, $S_{f}=S_{f_{m}}+S_{f_{0}}$ [34]. For an ideal PV cell, $S_{f_{0}}=0$. The compilation of these two equations allows to rewrite equation (24) as follows:

$$
J_{p h_{j, k}}=\frac{e R_{j, k}}{g_{x} g_{y}} \frac{D_{n}^{*}}{D_{j, k}} S_{f_{m}} Z_{j, k}(0)+\frac{e R_{j, k}}{g_{x} g_{y}} \frac{D_{n}^{*}}{D_{j, k}} Z_{j, k}(0)\left[\mu_{n}^{*} E_{0} \frac{D_{n}^{*}}{D_{j, k}}\right],
$$


where the transferred photocurrent can be defined by the following equation.

$$
J_{p h T}=\sum_{j} \sum_{k} \frac{e R_{j, k}}{g_{x} g_{y}} \frac{D_{n}^{*}}{D_{j, k}} S_{f_{m}} Z_{j, k}(0) .
$$

And the leakage photocurrent can be defined as shown by the following equation:

$$
J_{p h F}=\sum_{j} \sum_{k} \frac{e R_{j, k}}{g_{x} g_{y}}\left(\frac{D_{n}^{*}}{D_{j, k}}\right)^{2} Z_{j, k}(0) \mu_{n}^{*} E_{0} .
$$

2.5. Photovoltage Expression. The expression of the photovoltage is obtained by application of Boltzmann's relation. It is $[30,35]$

$$
V_{p h}=V_{T} \cdot \ln \left[1+\frac{N_{B}}{n_{i}^{2}} \int_{-g_{x} / 2}^{g_{x} / 2} \int_{-g_{y} / 2}^{g_{y} / 2} \delta(x, y, 0) d x d y\right] .
$$
lows:

After all compilations, the photovoltage becomes as fol-

$$
V_{p h}=V_{T} \cdot \ln \left[1+\frac{g_{x} g_{y}}{n_{0}} \sum_{j} \sum_{k} R_{j, k}\left(A_{j, k}+K_{j, k}\right)\right],
$$

where $R_{j, k}=4 \cdot \sin \left(C_{x j}\left(g_{x} / 2\right)\right) \sin \left(C_{y k}\left(g_{y} / 2\right)\right) / c_{x, j} \cdot c_{y, k}$ and $V_{T}$ is thermal voltage. $n_{0}=n_{i}^{2} / N_{B}$ wherein $n_{i}$ and $N_{B}$ are, respectively, the intrinsic carrier's density at the thermal equilibrium and the base doping density level.

2.6. Electrical Power Expressions. The electric power which will be calculated using global current will be named global electric power. The expression of the global electric power $[26,29,32,36]$ is given by the following equation.

$$
P_{e l}=V_{p h} \cdot J_{p h} .
$$

Equation (30) expresses of the transferred electric power.

$$
P_{e l T}=V_{p h} \cdot J_{p h T} \cdot
$$

The leakage electric power is expressed into the following equation.

$$
P_{e l F}=V_{p h} \cdot J_{p h F} .
$$

The evaluation of the different electric parameters versus electromagnetic field and illumination wavelength will be presented in Results and Discussions.

\section{Results and Discussions}

3.1. Current versus Electromagnetic Field. The electromagnetic field transports the energy at a high frequency from the emission antenna to the reception antenna [37]. The variation of the electromagnetic field depends on the reverse of the distance between the source and the PV cell. Figure 4 shows the evolution of the global photocurrent density when the electromagnetic field meets the polycrystalline solar cell.

The evolution of the photocurrent density is very weak for low values of $S_{f}$. It increases with the increase of the $S_{f}$ . In fact, normally, there is no crossing of the junction when the solar cell is in an open circuit (low $S_{f}$ ). But in a short circuit (great $S_{f}$ ), all the carrier's charges cross the junction to improve the photocurrent. In the presence of an electromagnetic field, an important current in the open circuit is created which can reach the short circuit situation current when the distance source-PV cell is weak. Some studies proved that for a magnetic field values lower than $10^{-5} \mathrm{~T}$ cannot influence the photocurrent $[22,38-40]$. The magnetic field which is greater than this value is able to cause an accumulation of the carrier's charge at the junction by deflection [11]. That accumulation of the carrier's charge will have an increase of the voltage as a consequence. Thus, the electric field is the main cause of the presence of the current in an open circuit situation. The electric field provides an enormous kinetic energy to electrons. Because of its orientation, it propels the charge carriers towards the emitter. This is what explains the increase in photocurrent density. The electric field brings the sufficient kinetic energy to the minority carrier's charge to cross the junction participating in the increase of the photocurrent $[6,12]$. The apparition of the current in the open circuit translates the presence of a leakage current into the junction.

Figure 5 presents the behaviour of the transferred photocurrent while the electromagnetic field varies.

There is no current for $S_{f}<2.10^{2} \mathrm{~cm} \cdot \mathrm{s}^{-1}$ normally without an electromagnetic field mainly for an ideal PV cell. However, the transferred photocurrent density begins always around the open circuit situation because of the presence of the electromagnetic field. Also, if the electromagnetic field is great, the transferred quantity of the carrier's charge rises abruptly. When the distance source-solar cell is weak, there is an augmentation of the electromagnetic field and particularly its electric component. This electric component comes in addition to the internal electricity created between the different doping levels around the space charge region (SCR). These electric fields raise the kinetic energy of the minority carrier's charge causing the increase of the transferred current. However, the values of the short circuit show an improvement compared to the known technology today [41, 42]. One part of the global photocurrent density is also lost. The next paragraph presents the evolution of this loss current. In Figure 6, the evolution of the leakage photocurrent density versus the electromagnetic field is shown.

Figure 6 presents the persistence of the loss up to the intermediate functioning point. It is in the intermediate circuit, from $10^{3} \mathrm{~cm} \cdot \mathrm{s}^{-1}$ to $10^{5} \mathrm{~cm} \cdot \mathrm{s}^{-1}$, that the optimum electrical outputs are found. The persistence of the loss, i.e., the leakage current up to this circuit, is a cause of the PV output deterioration. The leakage photocurrent density is mainly localized in the open circuit. It proves that the electric field brings the improvement of the crossing of the carrier's charge because it causes an increase of transferred photocurrent. The electric 


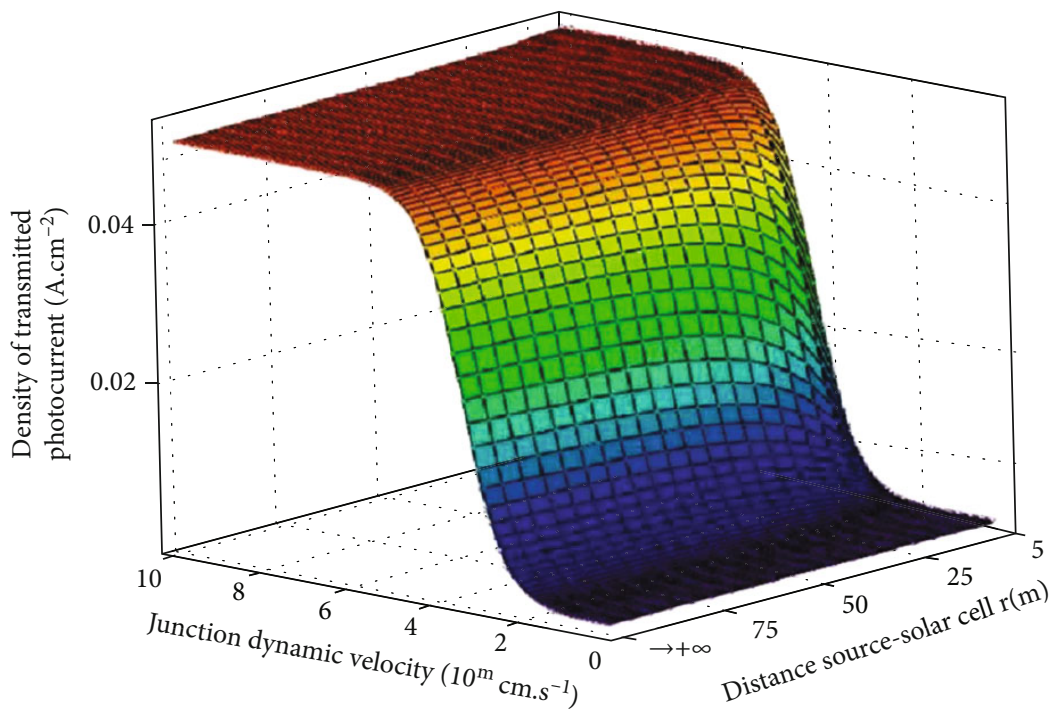

FIGURE 5: Transferred photocurrent versus junction dynamic velocity and emission distance-PV cell $\left(L_{n}=0.015 \mathrm{~cm}, D_{n}=26 \mathrm{~cm}^{2} \cdot \mathrm{s}^{-1}, \mu_{n}\right.$ $\left.=1000 \mathrm{~cm}^{2} \cdot \mathrm{V}^{-1} \cdot \mathrm{s}^{-1}, S_{b}=10^{4} \mathrm{~cm} \cdot \mathrm{s}^{-1}, S_{g b}=10^{3} \mathrm{~cm} \cdot \mathrm{s}^{-1}, g_{x}=g_{y}=3.10^{-2} \mathrm{~cm}, \lambda=0.70 \mu \mathrm{m}, H=0.03 \mathrm{~cm}\right)$.

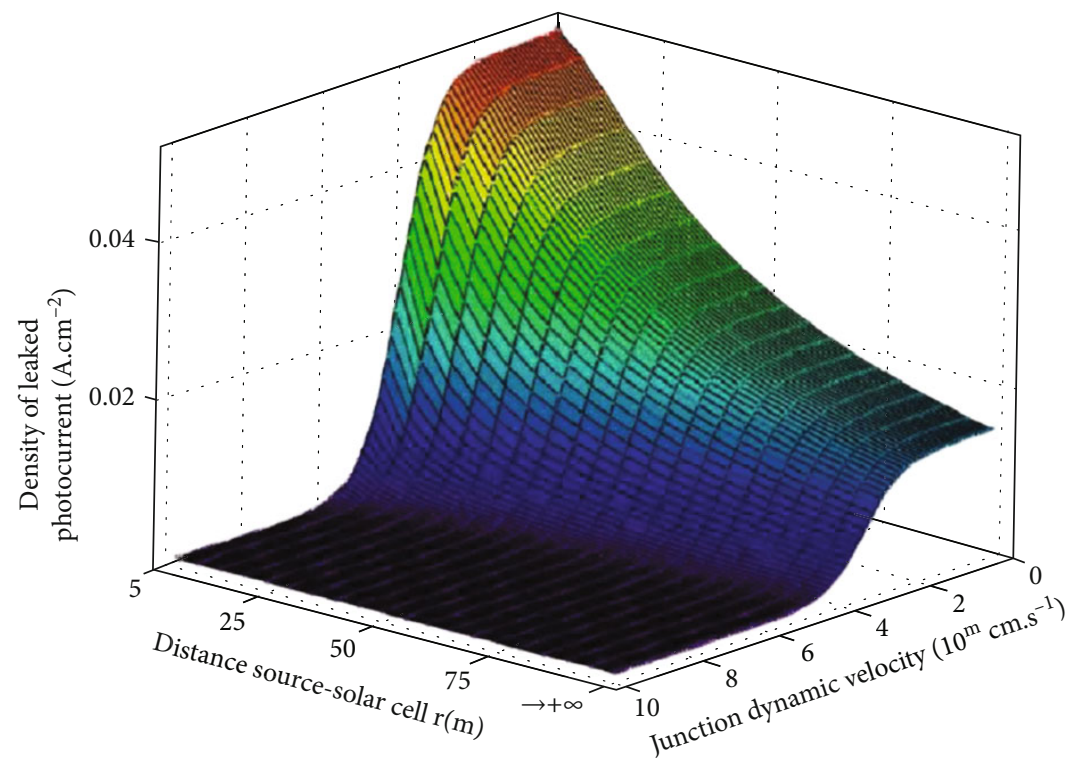

FIGURE 6: Leakage photocurrent versus junction dynamic velocity $\left(S_{f}\right)$ and distance emission source-PV cell $\left(L_{n}=0.015 \mathrm{~cm}, D_{n}=26 \mathrm{~cm}^{2}\right.$ $\left.\cdot \mathrm{s}^{-1}, \mu_{n}=1000 \mathrm{~cm}^{2} \cdot \mathrm{V}^{-1} \cdot \mathrm{s}^{-1}, S_{b}=10^{4} \mathrm{~cm} \cdot \mathrm{s}^{-1}, S_{g b}=10^{3} \mathrm{~cm} \cdot \mathrm{s}^{-1}, g_{x}=g_{y}=3.10^{-2} \mathrm{~cm}, \lambda=0.70 \mu \mathrm{m}, H=0.03 \mathrm{~cm}\right)$.

field from the electromagnetic field can bring down the accumulation of the electronic charge in the junction. However, the electromagnetic field is not the only parameter which influences the evolution of the photocurrent. Figure 7 shows the evolution of the density of the photocurrent for different illumination wavelengths.

The photocurrent density increases with the increase of the junction dynamic velocity from its low values to the larger values. The increase was also sensitive to the variation of the wavelength. Between $\lambda=0.38 \mu \mathrm{m}$ and $\lambda=0.70 \mu \mathrm{m}$, the photocurrent density is experiencing growth. In this range of wavelengths, the light depth penetration is low because the absorption coefficient is high and the reflection coefficient is weak. Accordingly, incident photons of this range of the wavelength release their energy to the charge carriers near the junction. The charge carriers helped by the internal electric field easily cross the junction to contribute to the photocurrent density. Then, from $\lambda=0.70 \mu \mathrm{m}$ to $\lambda=1.18 \mu \mathrm{m}$, there is a decrease in the photo production of charge carriers. Indeed, in this wavelength range, the absorption coefficient is low but the reflection coefficient is great, then the light depth penetration is very high. Consequently, the carrier's charges 


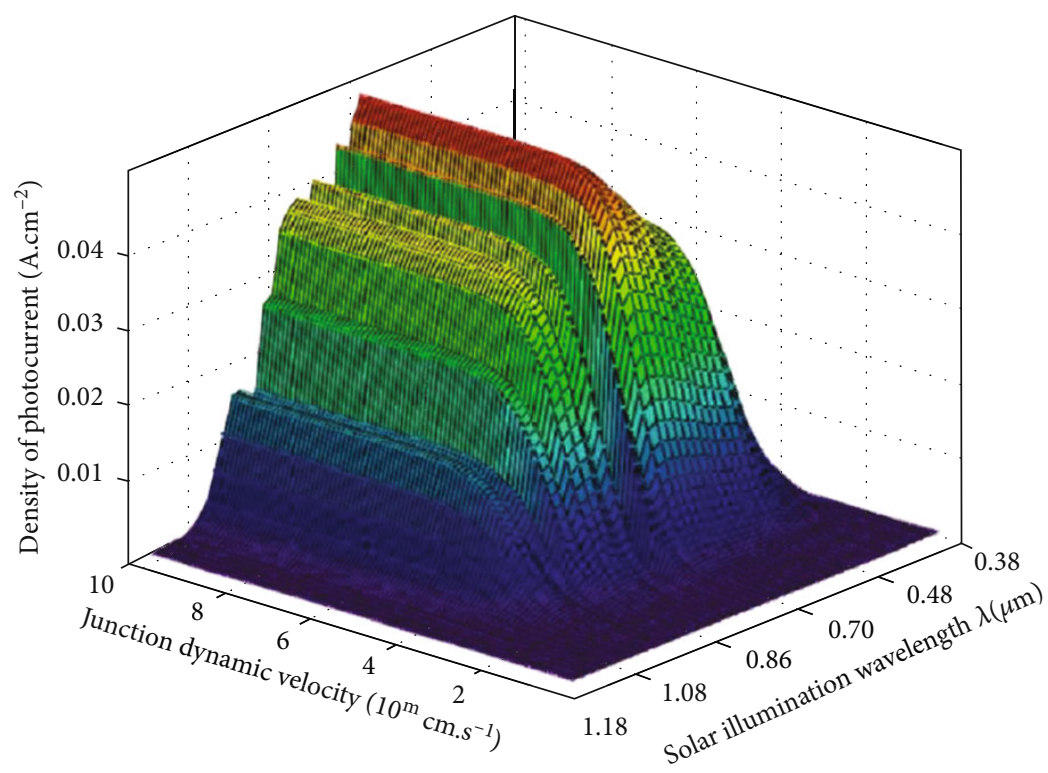

Figure 7: Global current versus junction dynamic velocity $\left(S_{f}\right)$ and solar illumination wavelength $\left(L_{\mathrm{n}}=0.015 \mathrm{~cm}, D_{n}=26 \mathrm{~cm}^{2} \cdot \mathrm{s}^{-1}, \mu_{n}=\right.$ $\left.1000 \mathrm{~cm}^{2} \cdot \mathrm{V}^{-1} \cdot \mathrm{s}^{-1}, S_{b}=10^{4} \mathrm{~cm} \cdot \mathrm{s}^{-1}, S_{g b}=3.10^{3} \mathrm{~cm} \cdot \mathrm{s}^{-1}, g_{x}=g_{y}=3.10^{-2} \mathrm{~cm}, r \longrightarrow+\infty, H=0.03 \mathrm{~cm}\right)$.

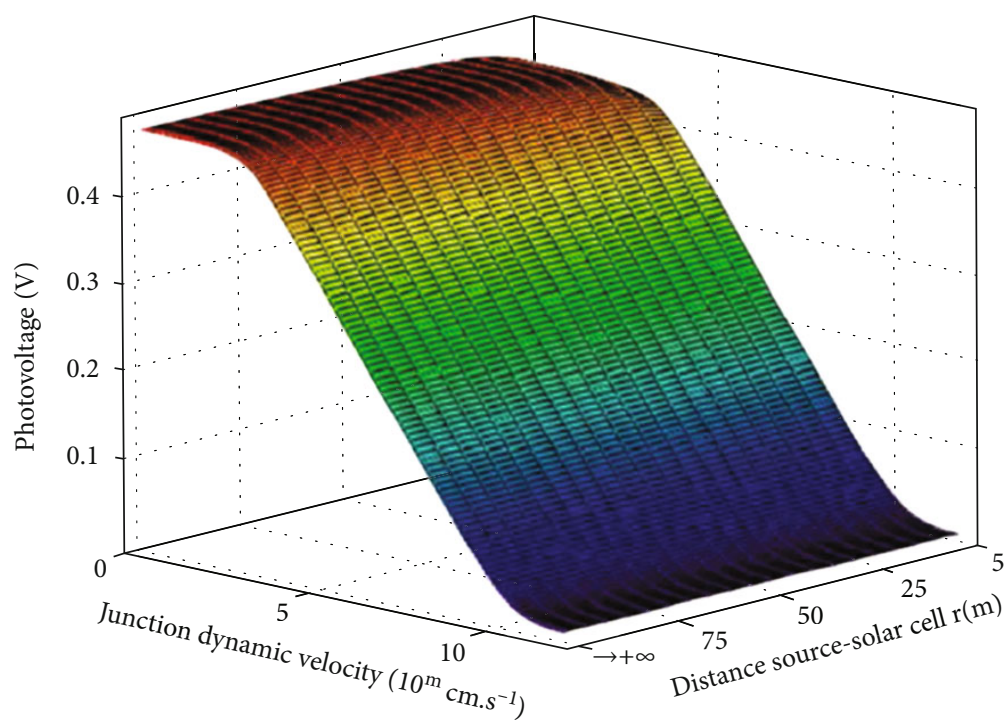

Figure 8: Photovoltage versus junction dynamic velocity $\left(S_{f}\right)$ and distance emission source-PV cell $\left(L_{n}=0.015 \mathrm{~cm}, D_{n}=26 \mathrm{~cm}^{2} \cdot \mathrm{s}^{-1}, \mu_{n}\right.$ $\left.=1000 \mathrm{~cm}^{2} \cdot \mathrm{V}^{-1} \cdot \mathrm{s}^{-1}, S_{b}=10^{4} \mathrm{~cm} \cdot \mathrm{s}^{-1}, S_{g b}=10^{3} \mathrm{~cm} \cdot \mathrm{s}^{-1}, g_{x}=g_{y}=3.10^{-2} \mathrm{~cm}, \lambda=0.70 \mu \mathrm{m}, H=0.03 \mathrm{~cm}\right)$.

are generated in the deep near the back rear side. At the rear side, the charge carriers are supported by the back surface field (BSF) which rejects the electrons towards the base. But, as these electrons do not have sufficient kinetic energy, they can be recombined or stored at the junction and contribute to the photovoltage. This reverse trend can be called the inversion phenomenon. The maximum photocurrent is obtained at $\lambda=0.70 \mu \mathrm{m}$, i.e., the red range in the solar illumination spectrum. The different deformations presented in Figure 7 are caused by the atmosphere gas absorption of solar radiation.
3.2. Photovoltage. The behaviour of the photovoltage versus electromagnetic field is shown in the following Figure 8

For the great value of the electromagnetic field (short distance source-solar cell), the photovoltage presents its weak values in open circuit. The photovoltage rises versus the decrease of the electromagnetic field, i.e., with the weak distance source-PV cell. The electromagnetic field, mainly its electric component, causes the crossing of the junction by the carrier charge. This crossing of the carrier's charge goes down, and the photovoltage decreases. The accumulation of the carrier's charge and the associated space- 


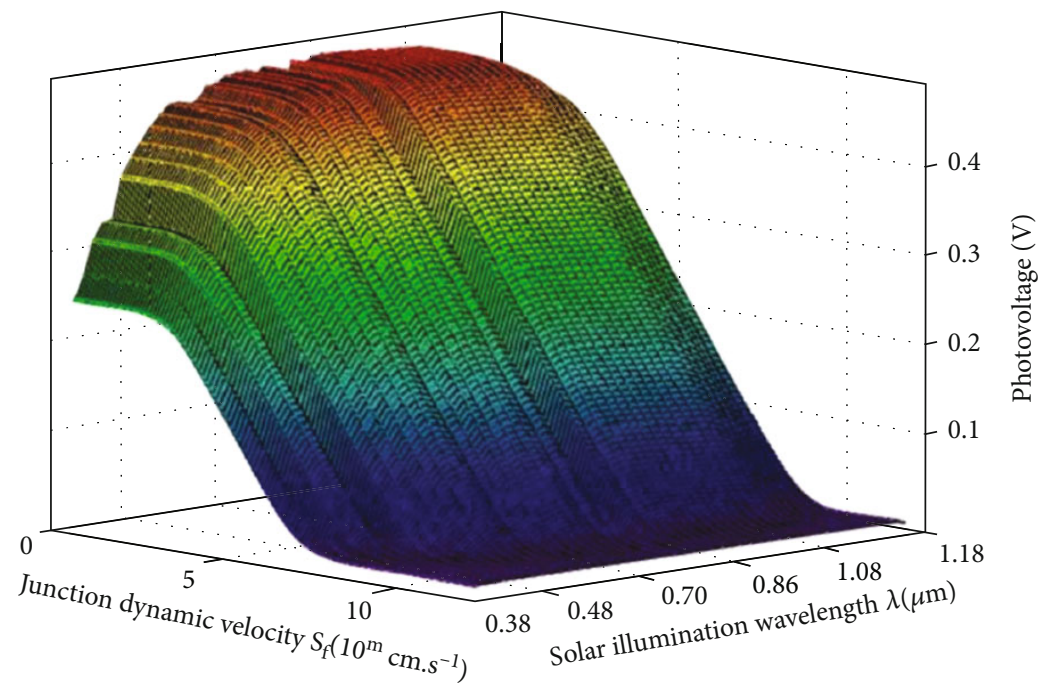

FIGURE 9: Photovoltage versus junction dynamic velocity $\left(S_{f}\right)$ and solar illumination wavelength $\left(L_{n}=0.015 \mathrm{~cm}, D_{n}=26 \mathrm{~cm}^{2} \cdot \mathrm{s}^{-1}, \mu_{n}=\right.$ $\left.1000 \mathrm{~cm}^{2} \cdot \mathrm{V}^{-1} \cdot \mathrm{s}^{-1}, S_{b}=10^{4} \mathrm{~cm} \cdot \mathrm{s}^{-1}, S_{g b}=3.10^{3} \mathrm{~cm} \cdot \mathrm{s}^{-1}, g_{x}=g_{y}=3.10^{-2} \mathrm{~cm}, r \longrightarrow+\infty, H=0.03 \mathrm{~cm}\right)$.

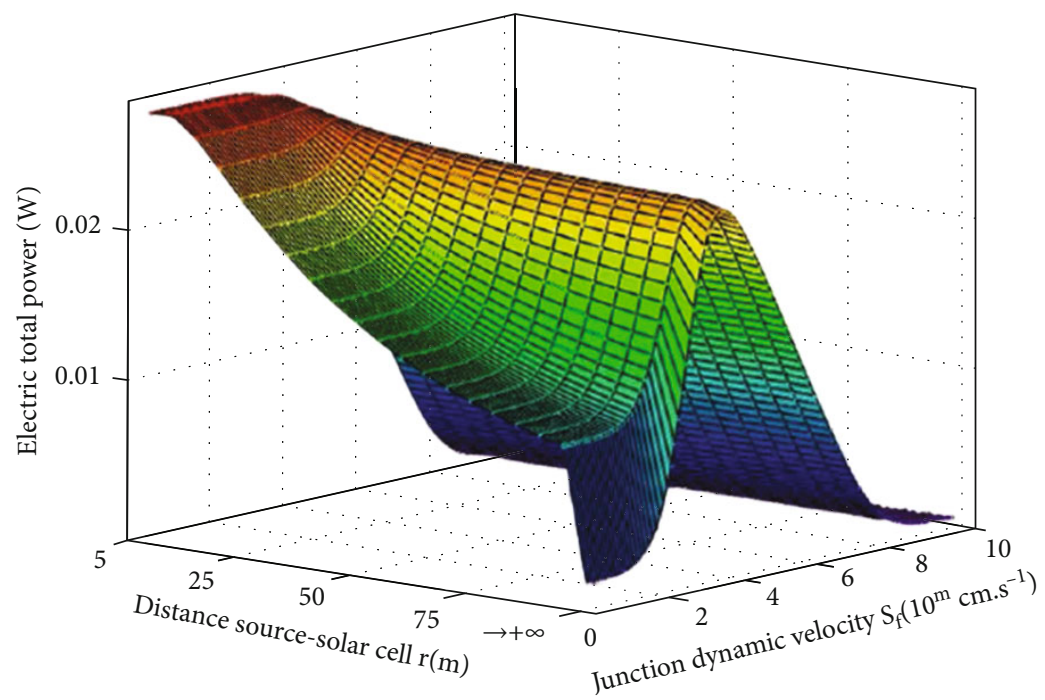

Figure 10: Global electric power versus dynamic velocity $\left(S_{f}\right)$ and of distance emission source-PV cell $\left(L_{n}=0.015 \mathrm{~cm} D_{n}=26 \mathrm{~cm}^{2} \cdot \mathrm{s}^{-1}\right.$, $\left.\mu_{n}=1000 \mathrm{~cm}^{2} \cdot \mathrm{V}^{-1} \cdot \mathrm{s}^{-1}, S_{b}=10^{4} \mathrm{~cm} \cdot \mathrm{s}^{-1}, S_{g b}=10^{3} \mathrm{~cm} \cdot \mathrm{s}^{-1}, g_{x}=g_{y}=3.10^{-2} \mathrm{~cm}, \lambda=0.70 \mu \mathrm{m}, H=0.03 \mathrm{~cm}\right)$.

charge-region recombination can reduce the short-circuit current in some cells [43]. The electromagnetic field reduces the recombination in the space-charge-region of the $p-n$ junction and leads to the storage reduction of the carrier's charge in this junction. The evolution of the photovoltage with the solar illumination is presented in Figure 9.

This figure shows the inversion phenomenon and the absorption of the solar radiation by the atmosphere gases. The maximum value is obtained at a wavelength of $0.70 \mu$ $\mathrm{m}$. The following section will present the influence of the electromagnetic field and solar illumination on the electric power.
3.3. Electric Power versus Electromagnetic Field. The presence of the electromagnetic field causes the loss of one part of the photocurrent. Then, considering the different parts of the photocurrent, it is possible to calculate the global electric power, the transmitted electric power, and the leakage electric power. Figure 10 gives the evolution of the electric power with distance emission source-solar cell and the dynamic velocity.

When the electromagnetic emission source is far away from the solar cell, there is no power in the open and short circuit situations. Only the intermediate circuit presents an electric power. This electric power decreases with the 


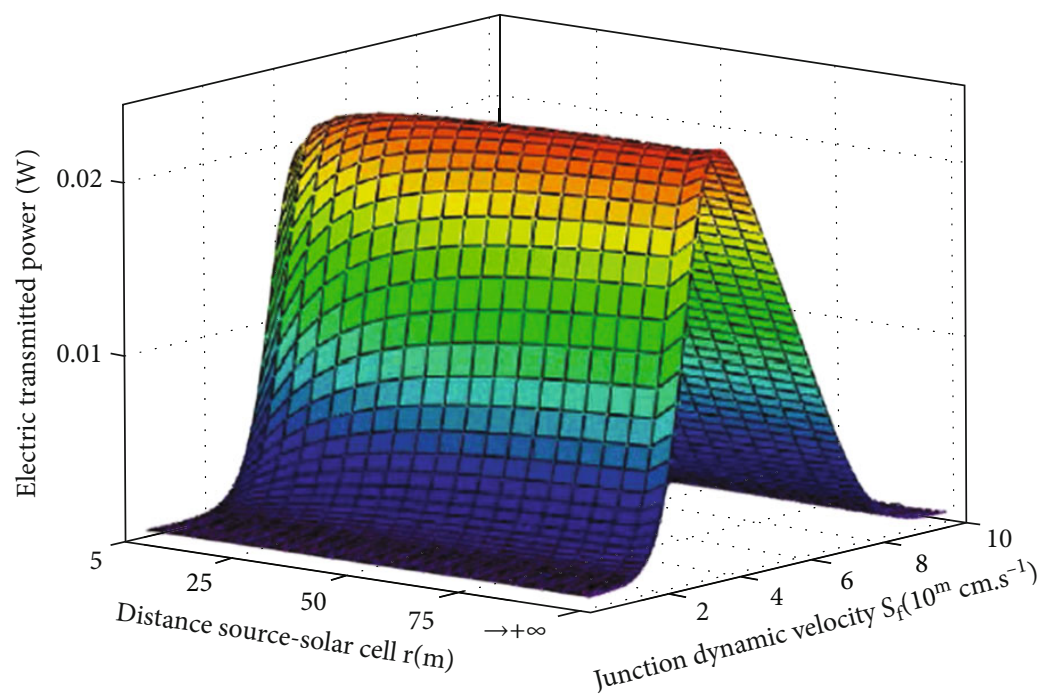

Figure 11: Transferred electric power versus junction dynamic velocity $\left(S_{f}\right)$ and distance emission source-PV cell $\left(L_{n}=0.015 \mathrm{~cm}, D_{n}=\right.$ $\left.26 \mathrm{~cm}^{2} \cdot \mathrm{s}^{-1}, \mu_{n}=1000 \mathrm{~cm}^{2} \cdot \mathrm{V}^{-1} \cdot \mathrm{s}^{-1}, S_{b}=10^{4} \mathrm{~cm} \cdot \mathrm{s}^{-1}, S_{g b}=10^{3} \mathrm{~cm} \cdot \mathrm{s}^{-1}, g_{x}=g_{y}=3.10^{-2} \mathrm{~cm}, \lambda=0.70 \mu \mathrm{m}, H=0.03 \mathrm{~cm}\right)$.

decrease of the distance source-solar cell, i.e., with the increase of the electromagnetic field. The value of the magnetic component of this field is very weak and cannot perturb the functioning of the solar cell. Then, the decrease of the electric power is caused by the electric field only. The electric component brings the kinetic energy to the minority carrier charge and leads its carrier's charge to cross the junction in importance. The electric field can be used to increase the minority diffusion length in a bulk semiconductor [44]. However, the great electric field causes the appearance of the electric power in open circuit called the leakage electric power. Hence, some part will be transmitted to the external circuit and the other part will be lost at the junction resulting in the reduction of the best quality of the solar cell.

The following Figure 11 gives the variation of transferred power in the function of the electromagnetic field and in the function of the dynamic velocity.

The electric power is obtained only in the intermediate circuit. Its maximum value decreases with the increase of the electromagnetic field. The maximum electric power shifts to the short circuit situation as the junction dynamic velocity becomes larger. This figure allows us to find the conversion efficiency for different distances of source-solar cells using equation (32) for the monochromatic illumination $[26,45]$.

$$
\eta=\frac{P_{\max }}{P_{a b}},
$$

where $P_{a b}=\left(\phi_{0}(\lambda) \cdot[1-\rho(\lambda)] \cdot h \cdot c\right) / \lambda$.

$\phi_{0}(\lambda)$ is the incident illumination flux in the number of photons per $\mathrm{cm}^{2}$ and per s, $\rho(\lambda)$ is the reflection coefficient of the frontal face of the solar cell, $h$ is the Planck constant in $\mathrm{J} \cdot \mathrm{s}, \mathrm{c}$ is the light vacuum speed in $\mathrm{cm} \cdot \mathrm{s}^{-1}$, and $\lambda$ is solar illumination wavelength in $\mathrm{cm}$.
TABLE 1: Maximum power and conversion efficiency for different distance emission source-PV cells $\left(L_{\mathrm{n}}=0.015 \mathrm{~cm}, D_{n}=26 \mathrm{~cm}^{2}\right.$. $\mathrm{s}^{-1}, \mu_{n}=1000 \mathrm{~cm}^{2} \cdot \mathrm{V}^{-1} \cdot \mathrm{s}^{-1}, S_{b}=10^{4} \mathrm{~cm} \cdot \mathrm{s}^{-1}, S_{g b}=10^{3} \mathrm{~cm} \cdot \mathrm{s}^{-1}, g_{x}$ $=g_{y}=3.10^{-2} \mathrm{~cm}, \lambda=0.70 \mu \mathrm{m}, H=0.03 \mathrm{~cm}$ ).

\begin{tabular}{lccc}
\hline$r(\mathrm{~m})$ & $S_{f_{\mathrm{MPP}}}\left(10^{m} \mathrm{~cm} \cdot \mathrm{s}^{-1}\right)$ & $P_{\max }\left(\mathrm{mW} \cdot \mathrm{cm}^{-2}\right)$ & $\eta(\%)$ \\
\hline 5 & 4.5 & 19.988 & 21.641 \\
25 & 4.0 & 22.797 & 24.683 \\
50 & 3.9 & 23.352 & 25.283 \\
75 & 3.9 & 23.520 & 25.465 \\
$\longrightarrow+\infty$ & 3.8 & 23.876 & 25.851 \\
\hline
\end{tabular}

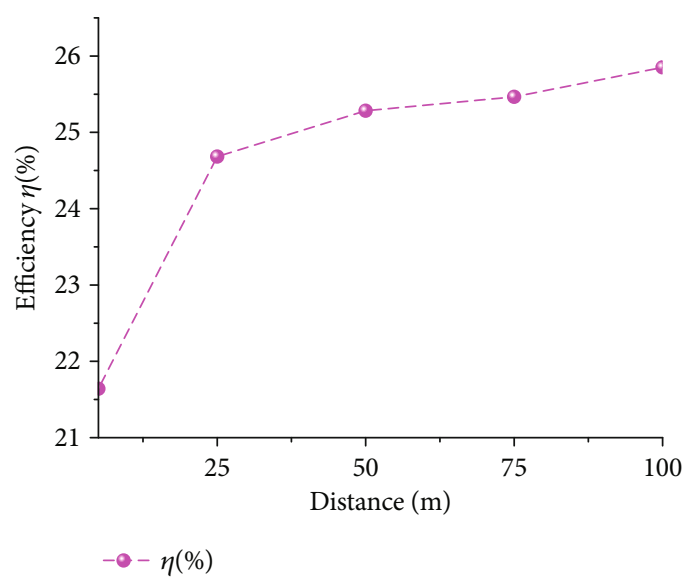

FIgURe 12: Conversion efficiency versus distance emission sourcePV cell. 


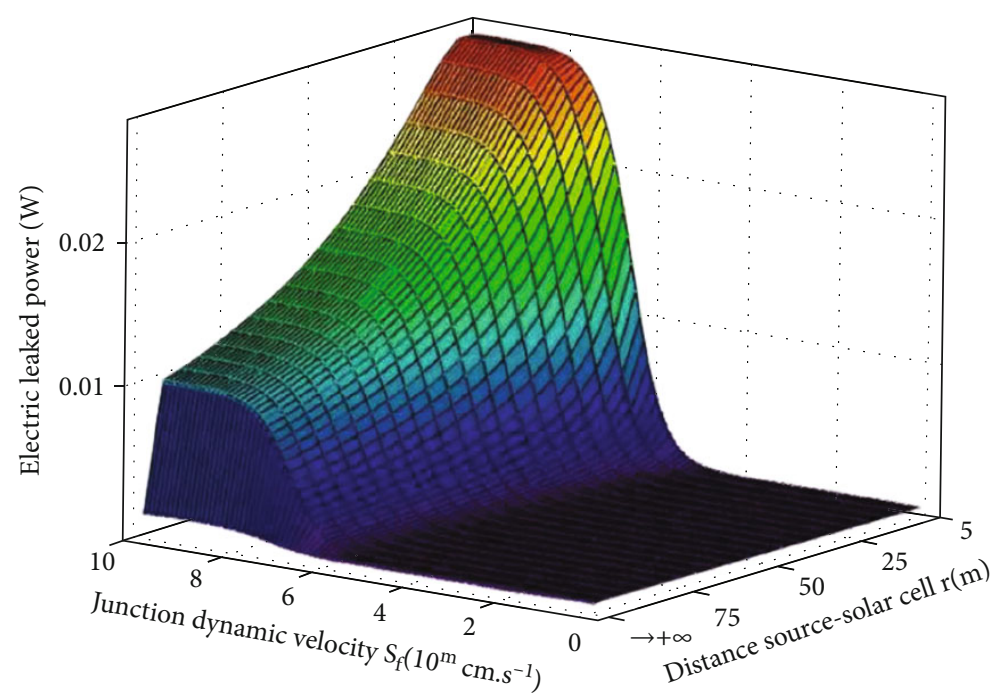

FIGURE 13: Leakage electric power in function of junction dynamic velocity $\left(S_{f}\right)$ and in function of distance source-solar cell $\left(L_{n}=0.015\right.$ $\left.\mathrm{cm}, D_{n}=26 \mathrm{~cm}^{2} \cdot \mathrm{s}^{-1}, \mu_{n}=1000 \mathrm{~cm}^{2} \cdot \mathrm{V}^{-1} \cdot \mathrm{s}^{-1}, S_{b}=10^{4} \mathrm{~cm} \cdot \mathrm{s}^{-1}, S_{g b}=10^{3} \mathrm{~cm} \cdot \mathrm{s}^{-1}, g_{x}=g_{y}=3.10^{-2} \mathrm{~cm}, \lambda=0.70 \mu \mathrm{m}, H=0.03 \mathrm{~cm}\right)$.

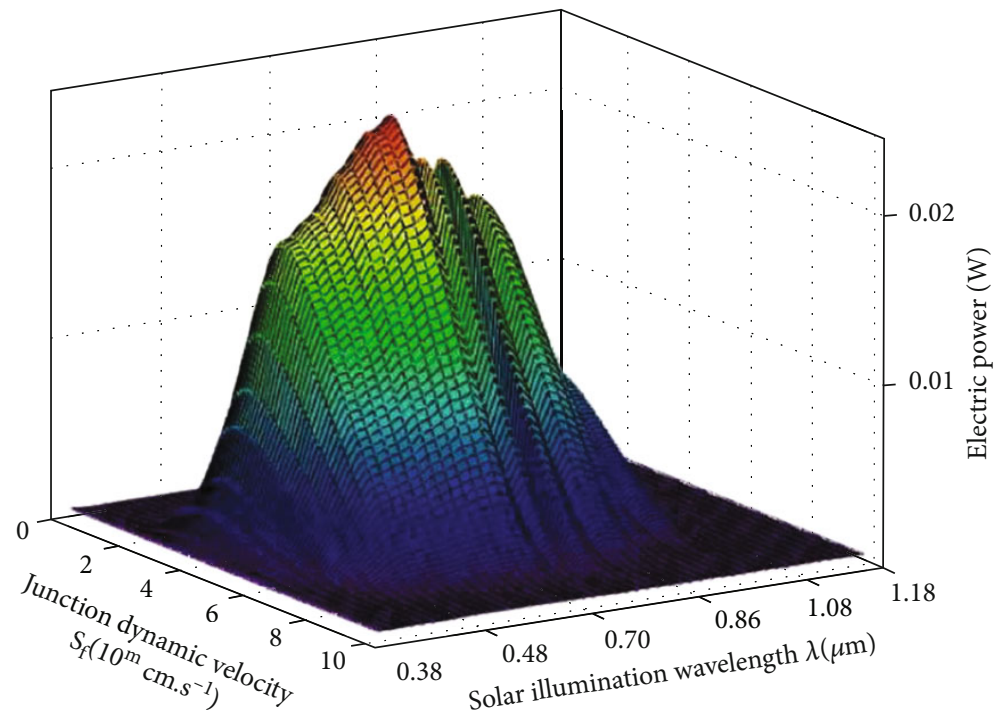

FIGURE 14: Electric power in function of junction dynamic velocity $\left(S_{f}\right)$ and solar illumination wavelength $\left(L_{n}=0.015 \mathrm{~cm}, D_{n}=26 \mathrm{~cm}\right.$. $\left.\mathrm{s}^{-1}, \mu_{n}=1000 \mathrm{~cm}^{2} \cdot \mathrm{V}^{-1} \cdot \mathrm{s}^{-1}, S_{b}=10^{4} \mathrm{~cm} \cdot \mathrm{s}^{-1}, S_{g b}=3.10^{3} \mathrm{~cm} \cdot \mathrm{s}^{-1}, g_{x}=g_{y}=3.10^{-2} \mathrm{~cm}, r \longrightarrow+\infty, H=0.03 \mathrm{~cm}\right)$.

The different efficiencies are presented in Table 1.

The better efficiency is obtained when the solar PV cell is too far from the electromagnetic field emission source. Figure 12 provides the conversion efficiency with the electromagnetic field.

The conversion efficiency increases when the PV system is far away from the telecommunication antenna. It will be better to avoid the installation of the PV system in the vicinity of the telecommunication antenna for the distance less than $100 \mathrm{~m}$.

This leakage of electric power is presented in Figure 13 in the function of the dynamic velocity and the distance source-solar cell.
The increase in the lost photocurrent density increases with the electromagnetic field. This means that the electromagnetic field causes a significant loss of the minority charge carriers in the junction when crossing this junction. The heating of the junction causes the quality reduction of the solar PV cell due to the electric component in particular. The next paragraph leads to the study of the electric power in the function of the wavelength of incident solar illumination.

The wavelength impact of the incident solar illumination is presented in Figure 14.

In this figure, the inversion phenomenon appears when the maximum value in the wavelength of $0.70 \mu \mathrm{m}$ is reached. 
TABLE 2: Maximum power and conversion efficiency for different solar illumination wavelengths $\left(L_{n}=0.015 \mathrm{~cm}, D_{n}=26 \mathrm{~cm}^{2} \cdot \mathrm{s}^{-1}\right.$, $\mu_{n}=1000 \mathrm{~cm}^{2} \cdot \mathrm{V}^{-1} \cdot \mathrm{s}^{-1}, S_{b}=10^{4} \mathrm{~cm} \cdot \mathrm{s}^{-1}, S_{g b}=3.10^{3} \mathrm{~cm} \cdot \mathrm{s}^{-1}, g_{x}=$ $\left.g_{y}=3.10^{-2} \mathrm{~cm}, r \longrightarrow+\infty, H=0.03 \mathrm{~cm}\right)$.

\begin{tabular}{lccc}
\hline$\lambda(\mu \mathrm{m})$ & $S_{f_{\mathrm{MPP}}}\left(10^{m} \mathrm{~cm} \cdot \mathrm{s}^{-1}\right)$ & $P_{\max }\left(\mathrm{mW} \cdot \mathrm{cm}^{-2}\right)$ & $\eta(\%)$ \\
\hline 0.38 & 3.7 & 3.8547 & 12.223 \\
0.48 & 3.8 & 17.341 & 17.772 \\
0.58 & 3.8 & 20.836 & 21.595 \\
0.70 & 3.8 & 23.876 & 25.851 \\
0.76 & 3.8 & 01.4692 & 1.591 \\
0.86 & 3.8 & 16.675 & 18.054 \\
0.96 & 3.7 & 7.1184 & 17.209 \\
\hline
\end{tabular}

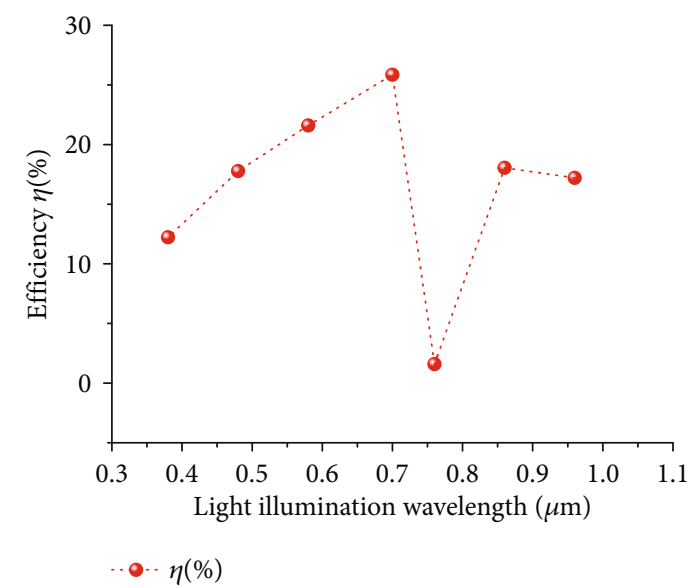

FIGURE 15: Conversion efficiency illumination wavelength.

In this figure, we observe the absorption of the solar radiation by the atmospheric gases. Here also, the conversion efficiencies for different wavelengths of the incident solar illumination has been determined. The values are presented in Table 2.

From $0.38 \mu \mathrm{m}$ to $0.70 \mu \mathrm{m}$, the conversion presents an improvement with the maximum efficiency obtained in $0.70 \mu \mathrm{m}$. From $0.70 \mu \mathrm{m}$ to $0.96 \mu \mathrm{m}$, the observation of the conversion presents the decrease of the efficiency. Figure 15 provides the influence of the wavelength on the conversion efficiency.

A strong absorption appears in the wavelength of 0.76 $\mu \mathrm{m}$ resulting to a weak value of the efficiency. This strong absorption is explained by the effects of steam water vapor on the solar radiation according to the analysis of the solar spectrum [46].

\section{Conclusion}

The presence of the electromagnetic field causes the creation of a conduction current in $3 \mathrm{D}$ modelling. The impact of the magnetic component of the electromagnetic field can be neglected compared to the impact of the electric component. Hence, the presence of the electric field provides the conduction current. The individual electric field or the electromagnetic field causes a decomposition of the current in the transferred current and in the leakage current. The current produced by the PV cell is sensitive to the electromagnetic field increase more than the electric voltage provided. The electric power is shared in two components taking into account the leakage and the transferred photocurrent. The electromagnetic field from a BTS provides an increase on the collection of the carrier's charge photo produced. However, this collection does not contribute to improvement of the conversion efficiency. Then, the maximum photocurrent can be found between $0.38 \mu \mathrm{m}$ and $0.70 \mu \mathrm{m}$ showing the inversion phenomenon. The best conversion efficiency is found in $0.70 \mu \mathrm{m}$. The study of an electromagnetic field effect and of the electric field effect must take into account the conduction current. The conduction current provides an increase of the current and contributes to the increase of the quantity of the extracted photocurrent of the solar cell. It is not advised to install a PV energy power plant near an electromagnetic field emission source. The efficiency of the conversion increases when the value of the electromagnetic field decreases, i.e., when the solar cell is too far from the emission source of this electromagnetic field.

\section{Data Availability}

(1) The [solar global radiation] data used to support the findings of this study have been deposited in the [A. M. Green 2008] repository [doi: 10.1016/j.solmat.2008.06.009]. (2) The silicon PV cell data used to support the findings of this study are included within the article of E. Seraffetin et al. 2006 doi:10.1016/j.solmat.2005.04.038 and 2008, I. Zerbo et al. 2014, A. Ouedraogo et al. 2018 10.4236/sgre.2018.912018, 2019 10.1007/s13369-019-03906-7, and 202110.1016 /j.rio.2021.100101. (3) The data about evolution of the electromagnetic field in PV cell used to support the findings of this study which are included within the supplementary information file(s) are provided by Ouedraogo et al. 2017 doi:10.3906/fiz-1703-16. 4. The above equation-solved data used to support the findings of this study have not been made available because the solution carrier transport and continuity equations are obtained manually.

\section{Conflicts of Interest}

The authors declare that they have no conflicts of interest.

\section{Acknowledgments}

The authors are thankful to the International Science Program (ISP) which is supporting our research group (energy and environment) and allowing the conduct of our works.

\section{References}

[1] P. Wurfel, "Physics of solar cells," in Die Deutsche Bibliothek, Wiley-VCH Verlag GmbH and Co., Berlin, KGaA edition edition, 2005. 
[2] S. Chander, A. Purohit, A. Sharma, S. P. Nehra, and M. S. Dhaka, "Impact of temperature on performance of series and parallel connected mono- crystalline silicon solar cells," Energy Reports, vol. 1, pp. 175-180, 2015.

[3] A. Ouedraogo, T. S. M. Ky, A. Compaore, and D. J. Bathiebo, "Improvement in the silicon solar cell performance by integration of the electric field source in the solar cell under sunlight illumination," Arabian Journal for Science and Engineering, vol. 44, no. 7, pp. 6651-6657, 2019.

[4] A. Ouédraogo, B. Zouma, E. Ouédraogo, L. Guissou, and D. J. Bathiébo, "Individual efficiencies of a polycrystalline silicon pv cell versus temperature," Results in Optics, vol. 4, no. 8, article 100101, 2021.

[5] Micro Vision Groupe, "Emf visual, electromagnetic exposure simulation software, application note," 2019, https://www .mvg-world.com/en/products/rf-safety.

[6] A. Ouedraogo, V. D. Barandja, I. Zerbo, M. Zoungrana, E. W. Ramde, and D. J. Bathiebo, "A theoretical study of radio wave attenuation through a polycrystalline silicon solar cell," Turkish Journal of Physics, vol. 41, pp. 314-325, 2017.

[7] M. Nicolas, Ondes et Électromagnétisme, Dunod, 2009.

[8] ICNIRP, "ICNIRP guidelines for limiting exposure to timevarying electric, magnetic and electromagnetic fields (up to 300 GHz)," Health Physics, vol. 74, no. 4, pp. 494-522, 1998.

[9] A. Ouedraogo, S. D. Bazyomo, S. Ouedraogo, A. Razakou, and D. J. Bathiebo, "Improvement of the silicon solar cell performance by integration of an electric field source in the solar cell or solar module system," Smart Grid and Renewable Energy, vol. 9, no. 12, pp. 285-298, 2018.

[10] S. Erel, M. Akçil, G. K. Erel, and V. Çelik, "The behaviour of a typical single-crystal si solar cell under high intensity of electric field," Solar Energy Materials \& Solar Cells, vol. 90, no. 5, pp. 582-587, 2006.

[11] E. Serafettin, "The effect of electric and magnetic fields on the operation of a photovoltaic cell," Solar Energy Materials \& Solar Cells, vol. 71, no. 2, pp. 273-280, 2002.

[12] I. Zerbo, M. Zoungrana, A. Ouedraogo, B. Korgo, B. Zouma, and D. J. Bathiebo, "Influence of electromagnetic waves produced by an amplitude modulation radio antenna on the electric power delivered by a silicon solar cell," Global Journal of Pure and Applied Sciences, vol. 20, no. 2, pp. 139-148, 2014.

[13] A. Moissi, M. Zoungrana, A. Diallo et al., "Base transceiver station (BTS) antenna electric field influence on the space charge region in a silicon solar cell," Research Journal of Applied Sciences, Engineering and Technology, vol. 7, no. 12, pp. 25542558, 2014.

[14] C. T. Sarr, M. M. Dione, S. Gaye, I. Gueye, A. Thiam, and G. Sissoko, "Effect of electric field on bifacial polycrystalline silicon solar cell under multispectral light," International Journal of Electrical Engineering, vol. 2, no. 9, 2014.

[15] Y. Betser, D. Ritter, G. Bahir, S. Cohen, and J. Sperling, "Measurement of the minority carrier mobility in the base of heterojunction bipolar transistors using a magnetotransport method," Applied Physics Letters, vol. 67, no. 13, pp. 18831884, 1995.

[16] R. Sam, B. Zouma, F. Zougmoré, Z. Koalaga, M. Zoungrana, and I. Zerbo, "3D determination of the minority carrier lifetime and the p-n junction recombination velocity of a polycrystalline silicon solar cell," in IOP Conference Series: Materials Science and Engineering, Volume 29, 1st Interna- tional Symposium on Electrical Arc and Thermal Plasmas in Africa (ISAPA), vol. 29, Ouagadougou, Burkina Faso, 2012.

[17] J. Furlan and S. Amon, "Approximation of the carrier generation rate in illuminated silicon," Solid-State Electronics, vol. 28, no. 12, pp. 1241-1243, 1985.

[18] J. G. Fossum and D. S. Lee, "A physical model for the dependence of carrier lifetime on doping density in nondegenerate silicon," Solid-State Electronics, vol. 25, no. 8, pp. 741-747, 1982.

[19] N. C. Halder and T. R. Williams, "Grain boundary effects in polycrystalline silicon solar cells I. Solution of the threedimensional diffusion equation by the Green's function method," Solar Cells, vol. 8, no. 3, pp. 201-223, 1983.

[20] P. Basore, "Defining terms for crystalline silicon solar cells," Progress in Photovoltaics: Research and Applications, vol. 2, no. 2, pp. 177-179, 1994.

[21] I. Zerbo, M. Saria, M. Zoungrana, A. Ouedraogo, and D. J. Bathiebo, "Effect of incidence angle varying from $0 \mathrm{rad}$ to $\pi /$ $2 \mathrm{rad}$ and intensity of radio waves on the performance of a silicon solar cell," Advances in Science and Technology. Research Journal, vol. 11, no. 4, pp. 68-75, 2017.

[22] M. L. Samb, M. Zoungrana, R. Sam, M. M. Dione, M. M. Deme, and G. Sissoko, "Etude en modélisation à 3D dune photopile au silicium en régime statique placée dans un champ magnétique et sous éclairement multispectral: détermination des paramètres électriques," Journal des Sciences, vol. 10, no. 4, pp. 23-38, 2010.

[23] IUT, Rec. itu-r bs.1698, recommendation itu-r bs.1698, evaluating fields from terrestrial broadcasting transmitting systems operating in any frequency band for assessing exposure to non-ionizing radiation (question itu-r 50/6), IUT, 2005, Technical report.

[24] I. Zerbo, M. Zoungrana, A. D. Sere et al., "Influence d'une onde électromagnetique sur une photopile au silicium sous éclairement multispectral en regime statique," Revue des Energies Renouvelables, vol. 14, no. 3, pp. 517-532, 2011.

[25] I. Zerbo, M. Zoungrana, A. D. Sere, and F. Zougmore, "Silicon solar cell under electromagnetic wave in steady state: effect of the telecommunication source's power of radiation," in IOP Conference Series: Materials Science and Engineering, vol. 29, Ouagadougou, Burkina Faso, 2012.

[26] H. Mathieu and H. Fanet, Physique des semiconducteurs et des composants électroniques, Dunod, 6 edition edition, 2009.

[27] A. Goetzberger, J. Knobloch, and B. Voss, Crystalline Silicon Solar Cells, John Wiley \& Sons Ltd, 1998.

[28] W. Shockley and W. T. Read, "Statistics of the recombinations of holes and electrons," Physical Review, vol. 87, no. 5, pp. 835842, 1952.

[29] B. Equer, "Physique et technologie de la conversion photovoltaïque : energie solaire photovoltaïque," in Ecole d'et'e: Electricit'e solaire pour les zones Rurales et isol'ees, vol. 1, UNESCO, 1991.

[30] J. Dugas, “3D modelling of a reverse cell made with improved multicrystalline silicon wafers," Solar Energy Materials and Solar Cells, vol. 32, no. 1, pp. 71-88, 1994.

[31] J. Dugas and J. Oualid, "A model of the dependence of photovoltaic properties on effective diffusion length in polycrystalline silicon," Solar Cells, vol. 20, no. 3, pp. 167-176, 1987.

[32] A. Moliton, Electronique et photo - électronique des matériaux et composants 2: photo - électronique et composants, Hermes Science, 2009. 
[33] F. Toure, M. Zoungrana, B. Zouma et al., "Influence of magnetic field on electrical model and electrical parameters of a solar cell under intense multispectral illumination," Global Journal of Science Frontier Research Physics and Space Sciences, vol. 12, no. 6, pp. 50-59, 2012.

[34] I. Zerbo, M. Zoungrana, A. Ouedraogo, and D. J. Bathiebo, "Effect of junction quality on the performance of a silicon solar cell," Journal of Fundamental and Applied Sciences, vol. 9, no. 2, pp. 1012-1026, 2017.

[35] N. C. Halder and T. R. Williams, "Grain boundary effects in polycrystalline silicon solar cells II: numerical calculation of the limiting parameters and maximum efficiency," Solar Cells, vol. 8, no. 3, pp. 225-238, 1983.

[36] A. Moliton, Electronique et optoélectronique organiques, Hermes Science Publications, France, 2011.

[37] A. Ducros, Les antennes, theorie et pratique, emission et reception, Elektor publitonic, Pays-Bas, 3e edition edition, 2008.

[38] I. Zerbo, M. Zoungrana, I. Sourabie, A. Ouedraogo, B. Zouma, and D. J. Bathiebo, "External magnetic field effect on bifacial silicon solar cell's electric power and conversion efficiency," Turkish Journal of Physics, vol. 39, no. 39, pp. 288-294, 2015.

[39] I. Zerbo, M. Zoungrana, I. Sourabié, A. Ouedraogo, B. Zouma, and D. J. Bathiebo, "External magnetic field effect on bifacial silicon solar cell's electrical parameters," Energy and Power Engineering, vol. 8, no. 3, pp. 146-151, 2016.

[40] M. Diaw, B. Zouma, A. Sere, S. Mbodji, A. G. Camara, and G. Sissoko, "3D study to improve the IQE of the bifacial polycrystalline silicon solar cell from the grain's geometries and the applied magnetic field," International Journal of Engineering Science and Technology, vol. 4, no. 8, pp. 3673-3682, 2012.

[41] A. M. Green, K. Emery, Y. Hishikawa, W. Warta, and E. D. Dunlop, "Solar cell efficiency tables (version 46)," Progress in Photovoltaics: Research and Applications, vol. 23, no. 7, pp. 805-812, 2015.

[42] A. M. Green, K. Emery, Y. Hishikawa, W. Warta, and E. D. Dunlop, "Solar cell efficiency tables (version 48)," Progress in Photovoltaics: Research and Applications, vol. 24, no. 7, pp. 905-913, 2016.

[43] K. Misiakos and F. A. Lindholm, "Minority-carrier accumulation at the base edge of a junction space-charge region under short-circuit conditions," Solid-State Electronics, vol. 30, no. 7, pp. 755-758, 1987.

[44] A. L. Fahrenbruch and R. H. Bube, Fundamentals of Solar Cells, Photovoltaic Solar Energy conversion. Stanford university, 1983.

[45] A. Correa, Modelisation de la recombinaison aux interfaces d'une photopile au silicium polycristallin en regime stationnaire. Thése de $3 e$ cycle, Universit'e Cheikh Anta Diop de Dakar, 1996.

[46] J. P. Triplet and G. Roche, Météorologie Générale, Météo, France, troisième édition 1986 edition edition, 1996. 